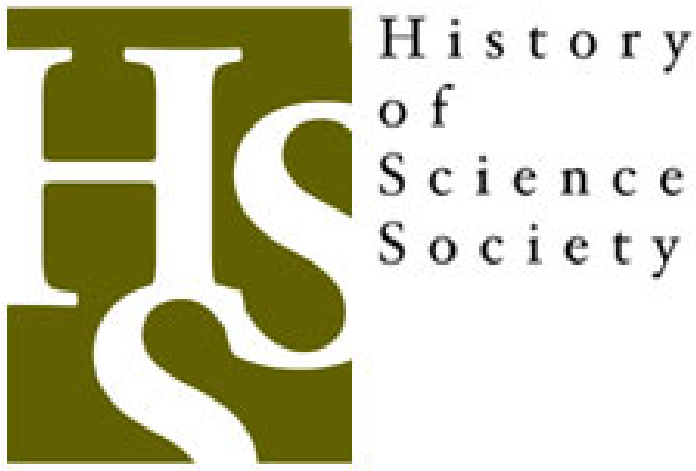

History of Mathematics and History of Science

Author(s): Tony Mann

Reviewed work(s):

Source: Isis, Vol. 102, No. 3 (September 2011), pp. 518-526

Published by: The University of Chicago Press on behalf of The History of Science Society

Stable URL: http://www.jstor.org/stable/10.1086/661626

Accessed: 02/11/2011 12:48

Your use of the JSTOR archive indicates your acceptance of the Terms \& Conditions of Use, available at http://www.jstor.org/page/info/about/policies/terms.jsp

JSTOR is a not-for-profit service that helps scholars, researchers, and students discover, use, and build upon a wide range of content in a trusted digital archive. We use information technology and tools to increase productivity and facilitate new forms of scholarship. For more information about JSTOR, please contact support@jstor.org.

The University of Chicago Press and The History of Science Society are collaborating with JSTOR to digitize, preserve and extend access to Isis. 


\title{
History of Mathematics and History of Science
}

\author{
By Tony Mann*
}

\begin{abstract}
This essay argues that the diversity of the history of mathematics community in the United Kingdom has influenced the development of the subject and is a significant factor behind the different concerns often evident in work on the history of mathematics when compared with that of historians of science. The heterogeneous nature of the community, which includes many who are not specialist historians, and the limited opportunities for academic careers open to practitioners have had a profound effect on the discipline, leading to a focus on elite mathematics and great mathematicians. More recently, reflecting earlier developments in the history of science, an increased interest in the context and culture of the practice of mathematics has become evident.
\end{abstract}

G IVEN THE INTIMATE RELATIONSHIP between mathematics and many of the sciences, one might expect that the history of mathematics would be a significant part of the history of science and might even be regarded as a subset of that discipline. However, the two subjects currently seem to have separated, with independent practitioners, to some extent different concerns and approaches, and relatively little interaction. This essay will attempt to examine some of the reasons for this apparent divergence, focusing on the situation in the United Kingdom. My argument is that the peculiar nature of the history of mathematics community has been the key factor influencing the speed with which new concerns among historians of science have spread to the history of mathematics.

The history of mathematics community is naturally small, but it is also remarkably diverse. Broadly, it includes academic specialists in the history of mathematics; practicing or retired academic or industrial mathematicians, engineers, and others with an active research or teaching interest in the history of the subject; popular writers on the subject; school or college teachers and teacher trainers who use the history of mathematics to motivate their students in mathematics classes; and possibly a few others-and there is a certain amount of overlap.

\footnotetext{
* Department of Mathematical Sciences, University of Greenwich, Old Royal Naval College, Park Row, London SE10 9LS, United Kingdom.
} 
Academic specialists are few in number, typically employed in various faculties in U.K. universities, including mathematics, general history, history of science, art history, and even English; there are also a number employed in the museum world. They often have formal historical training and naturally approach the subject from that angle. The Centre for the History of Mathematics at the Open University is, I believe, the only formally constituted academic center for the subject in the United Kingdom. Other historians of mathematics in universities occupy posts that are rarely dedicated specifically to that subject, so that on their retirement the research activity may not be continued in the department or institution, and succession in this academic community may be largely a matter of chance: however (perhaps surprisingly), a number of very talented historians have successfully made careers in this area. Changes to university financing, and the new "impact" criterion for research funding, may make such a career path even more difficult in the future.

Practicing mathematicians often develop an interest in the history of their subject and work in this area alongside their mathematical research: for example, Peter Neumann's work on the history of group theory sits alongside his contributions to the field. The London Mathematical Society and the American Mathematical Society produce a series of books on the history of mathematics that may appeal particularly to mathematicians (I should declare an interest as a member of the editorial board). In terms of university teaching, the recent focus by the Quality Assurance Agency (QAA) on developing graduate skills such as communication and critical thinking has encouraged the teaching of history of mathematics modules — seen as a way to address these skills- to mathematics undergraduates in the United Kingdom, and more than twenty universities appear currently to offer such modules (although with the removal of subject audits by the QAA, some of them may no longer be delivered). These modules are often taught by a mathematician rather than by a historian. Many of them are excellent and historically informed, and many of those delivering them have contributed significantly to the literature, even if their primary research interest is in mathematics itself. Books such as Luke Hodgkin's A History of Mathematics: From Mesopotamia to Modernity and Jeremy Gray's Worlds Out of Nothing have their origins in such courses (the former author is primarily a mathematician and the latter a historian). ${ }^{1}$ These courses may to some extent attempt to encourage mathematics undergraduates to adopt historical approaches, although the time available and the background of many students make this a considerable challenge. But many of today's historians of mathematics developed their interest in the field through such undergraduate modules - notably those who were influenced by the late David Fowler at Warwick University - and so this strand is of considerable importance for the future health of the history of mathematics in the United Kingdom.

Similarly, while many enthusiastic mathematics schoolteachers have always been drawn to history and have used historical material to inspire their learners, the recent move by the Qualifications and Curriculum Development Agency (QCDA) to include "historical and cultural context" in the school mathematics curriculum has perhaps been driven not so much by intrinsic enthusiasm for the subject as by the need to conform to the policy that every subject should address topics such as diversity, which are not always easy to find in traditional mathematics curricula. Whatever the motive, this stipulation neverthe-

\footnotetext{
${ }^{1}$ Luke Hodgkin, A History of Mathematics: From Mesopotamia to Modernity (Oxford: Oxford Univ. Press, 2005); and Jeremy Gray, Worlds Out of Nothing: A Course in the History of Geometry in the Nineteenth Century (London: Springer, 2007).
} 
less presents an opportunity for those of us who believe that the history of mathematics is a valuable educational tool. It remains to be seen how, following the proposed abolition of the QCDA, this aspect of the curriculum will develop.

School and college teachers (and indeed many university teachers who teach mathematics courses rather than dedicated history of mathematics modules) often wish to include historical material as a means of motivating their students and showing the human side of mathematics. While the material produced may be aimed at exciting learners rather than leading them to a deep understanding of historical issues, this section of the community is very active and vital to the development of the subject, and many of the practitioners are historically informed and have contributed significantly to the historical as well as to the pedagogical literature. Here one should mention the support offered by organizations such as History and Pedagogy of Mathematics, an international study group on the relations between history and pedagogy of mathematics that is affiliated with the International Commission on Mathematical Instruction.

There has been a long tradition of popular writing in the history of mathematics, going back to E. T. Bell's Men of Mathematics, a racy account that inspired many of today's historians-who, however, uniformly condemn Bell's preference for colorful stories over accurate history. Editors like Raymond Flood and his various collaborators have shown in a range of accessible collections of essays that reliability need not come at the expense of readability. Dava Sobel's surprise 1995 best-seller Longitude created, or showed the existence of, an unexpected popular market; not long after, Ian Pears's An Instance of the Fingerpost demonstrated that serious historical fiction could also find a large readership. ${ }^{2}$ More recently, authors like Ian Stewart, Robin Wilson, and Marcus du Sautoy have used the history of mathematics to inspire and educate large numbers - they are particularly popular with undergraduates-while the excellent history of science series from the publisher Icon has brought academic historians to a popular audience. There have been gratifyingly large fields for the Neumann Prize of the British Society for the History of Mathematics (BSHM), inaugurated in 2009 to recognize a book intended for a broad audience. Du Sautoy has subsequently put together a four-part TV series and a series of radio broadcasts on the history of mathematics. ${ }^{3}$

The subject also attracts adherents from outside these categories, often people with deep knowledge who have devoted much time to a particular interest. Sometimes they pursue hobbyhorses, but often they make valuable contributions to the field. One notable exam-

\footnotetext{
${ }^{2}$ E. T. Bell, Men of Mathematics (London: Gollancz, 1937) (there have been many subsequent editions); John Fauvel, Raymond Flood, Michael Shortland, and Robin J. Wilson, eds., Let Newton Be! (Oxford: Oxford Univ. Press, 1998); Fauvel, Flood, and Wilson, eds., Mobius and His Band: Mathematics and Astronomy in Nineteenth-Century Germany (Oxford: Oxford Univ. Press, 1993); Fauvel, Flood, and Wilson, eds., Oxford Figures: Eight Hundred Years of the Mathematical Sciences (Oxford: Oxford Univ. Press, 1999); Martin Campbell-Kelly, Mary Croarken, Flood, and Eleanor Robson, eds., The History of Mathematical Tables: From Sumer to Spreadsheets (Oxford: Oxford Univ. Press, 2003); Fauvel, Flood, and Wilson, eds., Music and Mathematics: From Pythagoras to Fractals (Oxford: Oxford Univ. Press, 2003); Dava Sobel, Longitude: The True Story of a Lone Genius Who Solved the Greatest Scientific Problem of His Time (New York: Walker, 1995); and Ian Pears, An Instance of the Fingerpost (London: Cape, 1997).

${ }^{3}$ For the Icon books see, e.g., Jon Agar, Turing and the Universal Machine: The Making of the Modern Computer (Cambridge: Icon, 2001); John Henry, Moving Heaven and Earth: Copernicus and the Solar System (Cambridge: Icon, 2001); Stephen Pumphrey, Latitude and the Magnetic Earth (Cambridge: Icon, 2002); and Patricia Fara, Fatal Attraction: Magnetic Mysteries of the Enlightenment (Thriplow: Icon, 2005). The 2009 Neumann Prize was awarded to Reviel Netz and William Noel, The Archimedes Codex: How a Medieval Prayer Book Is Revealing the True Genius of Antiquity's Greatest Scientist (London: Weidenfeld \& Nicolson, 2007). For Marcus du Sautoy's series see The Story of Mathematics (BBC4, 2008), available on DVD (Open Univ. Worldwide/BBC, 2008); and A Brief History of Mathematics (BBC Radio 4, 2010).
} 
ple, showing that mathematical or historical training is not a prerequisite for outstanding work in the field, is the late Mary Cannell (1913-2000), whose interest in local history led her after her retirement to work on George Green, producing a highly regarded biography. ${ }^{4}$

The range of books on the history of mathematics-serious scholarly histories, technical accounts, popular versions, textbooks, sourcebooks, and even fiction-has grown over the last thirty years even as the uptake of mathematics at school and university has declined and the level of public understanding of the subject is perceived to have fallen. The (relatively recent) specialist academic journals devoted to the subject-such as Historia Mathematica (founded in 1971) and the BSHM Bulletin (published as a journal since 2006) - appear to be thriving, while many papers on the subject are still published in other relevant journals.

Mention must be made of the outstanding Web resource on the history of mathematics, the MacTutor archive, created and maintained by two mathematicians, John J. O'Connor and Edmund F. Robertson, at the University of St. Andrews. ${ }^{5}$ This currently includes 2,118 biographies and over 4,000 pictures of mathematicians. It records about 2 million file accesses each week, which reflects its use worldwide. Such a reach must have been unimaginable when MacTutor was first conceived. There is no doubt that much of the work now taking place in the history of mathematics would be impossible without this archive: the use of history of mathematics in education, at the school and the undergraduate level, is so greatly facilitated by MacTutor that I believe the growth in interest in history in mathematics education could not have occurred without the archive.

One measure of the health of a discipline is its visibility. It seems to me that there can be no doubt that the literature on the history of mathematics, at all levels, has expanded to a degree unprecedented in any similar period since my student days in the 1970s. Whereas thirty years ago popular books on the history of mathematics were so rare that they had to be snapped up as soon as they appeared if one hoped to obtain a copy, books are now appearing at such a rate that even the most ardent devotee cannot keep up. Anyone with internet access can get to a formidable amount of material, generally of excellent quality (even books from leading academic publishers now cite Wikipedia and the MacTutor archive), on almost any aspect of the history of mathematics. Original sources, formerly available only to users of the largest libraries, are now readily available through several excellent sourcebooks, while even manuscript sources are often accessible digitally. Opportunities for the study of the history of mathematics abound.

As its current president, I would like to think that the British Society for the History of Mathematics, which was founded in 1971 at a meeting at Thames Polytechnic (the institution, now the University of Greenwich, where I have worked since 1989), not only exemplifies by its existence the growing interest in our subject, but has also helped create and strengthen this enthusiasm and supported scholars in the field. Similar bodies include the Canadian Society for History and Philosophy of Mathematics/Société Canadienne d'Histoire et de Philosophie des Mathématiques and the Indian Society for the History of Mathematics. There also exist a vast range of specialist societies, such as the British Sundial Society, the Scientific Instrument Society, and the Oughtred Society (for those interested in slide rules); indeed, the existence of specialist societies is sometimes given as a reason for declining memberships in more general organizations.

\footnotetext{
${ }^{4}$ D. M. Cannell, George Green: Mathematician and Physicist, 1793-1841: The Background to His Life and Work ([London]: Athlone, 1993).

${ }^{5}$ For the MacTutor History of Mathematics Archive see http://www-history.mcs.st-andrews.ac.uk/index.html.
} 
There is no shortage of workshops, seminars, and lectures on the history of mathematics. Organizations like the BSHM hold regular meetings: some on specific topics, others more general. Seminar series like EMPHASIS (Early Modern Philosophy and the Scientific Imagination Seminar) provide forums for discussion of the history of mathematics, often within a wider context. Of particular note is the annual BSHM Research in Progress day, a supportive conference for graduate students working in the area. Sessions on history of mathematics at events such as the British Science Festival and the British Mathematical Colloquium aim to promote interest in the subject in the wider mathematical and scientific communities. Gresham College in London has offered many excellent lectures on the history of mathematics, designed for a general audience, that are available worldwide in a rich video archive.

So one perspective on the current state of the history of mathematics in the United Kingdom is of a dynamic community with many opportunities for enthusiasts to participate in the subject. Despite this apparent upsurge in interest, however, there is reason for dismay at the relatively few opportunities for specialists: there is no evidence that the stream of popular literature is encouraging more professional entrants into the field, and given the lack of career possibilities this is hardly surprising. These contrasting aspects of the health of the community highlight the different elements it contains.

This rather lengthy introduction may seem to have little to do with the theme of this Focus section, but I believe that an understanding of the community is essential to an appreciation of its interactions with the history of science. First of all, the history of mathematics community is largely "amateur." I mean this in a very positive sense of the word: it refers to people whose day jobs lie elsewhere but who bring great passion, and very often valuable insights, to this interest. Most teaching and most dissemination of the history of mathematics in the United Kingdom is done by nonspecialists. The few professional historians offer a prominent lead, and the community is fortunate that outstanding historians such as Ivor Grattan-Guinness, Jeremy Gray, June Barrow-Green, Eleanor Robson, and Jacqueline Stedall have given enormous encouragement and guidance to students and to serious amateurs, promoting historians' attitudes and standards. There is a huge debt, especially, to the late John Fauvel, whose presence as facilitator, encourager, and inspiration before his untimely death in 2001 helped build the diverse community: without his influence, things would have been very different.

Whereas the history of science has some visibility as an academic discipline-there are university departments, there are taught master's programs, and there are career opportunities - things are rather different in the history of mathematics. There are no taught postgraduate programs to lead students into doctoral study, and there are few dedicated job opportunities. As a consequence, relatively few engage in full-time doctoral study, and many of the doctoral students in the United Kingdom are part-timers. (I find it remarkable that, in this situation, so many outstanding doctorates have been earned.) The greater professionalization of the history of science has resulted in a stronger, more unified academic discipline, more able to impose professional standards upon its practitioners.

There is a view that, while in the second half of the last century the history of science increasingly examined the context and cultures in which science was carried out, the history of mathematics was slow to follow that lead, continuing to focus on the work of great mathematicians, and that more recently the two fields have begun to come together again. I believe that there is a lot of truth in both halves of this assertion.

It is inevitable that the smaller field has had different preoccupations. Following Bell's notorious Men of Mathematics, historians of mathematics must have felt that there was a 
need to address the romanticized representation of their subject. It is entirely understandable that this would have led to a focus on mathematicians and their mathematics. The establishment of reliable accounts of the works of those the mathematics community regarded as the major figures had to be a priority.

Most historians of mathematics come from, in some sense, a mathematical rather than historical background: most originally studied mathematics or a mathematical science. The mathematics community has a rather old-fashioned view of their subject. Whereas science is increasingly seen as a collective activity, mathematics is often thought of by its practitioners as a solitary pursuit. In the stories we learn as students, mathematicians like Newton and Galois worked heroically alone (albeit for different reasons). Mathematicians are often Platonists, viewing mathematics as a body of necessary truths independent of social or cultural context. Whereas approaches to history change over time-we can no longer think of history as the study of great kings and queens-it was, and to some extent remains, plausible to consider mathematics as an area in which advances are made by individuals and context is irrelevant. Researchers were able to establish reputations without needing to strike out in new theoretical directions. So I think it is understandable that the history of mathematics, with a very small number of practitioners, has lagged behind the history of science in this respect.

Although historians warn against the dangers of whiggism, practicing mathematicians do see their subject in a very whiggish way. From the perspective of a practitioner, this is entirely reasonable: mathematicians are seeking more elegant proofs, generalizations of earlier results, better bounds, better solutions to old problems. To see mathematics as a process of continual improvement is quite natural, from this perspective, and it can be illuminating, especially for those who come to the history as practitioners of mathematics. But for most historians of mathematics today, presentism is an inappropriate approach to history. Tempting though it may be to attempt to present the mathematics of the past in the context and notation of today's mathematics, it is an invalid approach to history. Any deviation from the ideal historicist approach is a methodological error. From this perspective, the work of many amateurs, and especially that of some practicing mathematicians who turn to history, can be criticized, and this is where tensions between different parts of the community are apparent.

It is natural, in a field in which there are very few professional practitioners, and where these are often working with historians with a rather more sophisticated view of history than that of some mathematical amateur historians, that these professionals should insist on strict demarcations. For professionals, the subject's respectability in relation to other areas of history must be fought for, and this has perhaps been the defining issue for the field. The battles over the famous clay tablet Plimpton 322, anachronistically described by Sir Christopher Zeeman as "the statement of [a] classification theorem," exemplify this fault line in the community. ${ }^{6}$ (In 2007, when Zeeman presented his David Crighton Award lecture, provocatively entitled "What's Wrong with Euclid Book V?"- a fascinating talk, billed as "History of Mathematics," in which one of the world's greatest mathematicians adopted a contemporary practitioner's approach to an ancient text-the result may not have been historically informed analysis, but it was certainly thrilling mathematics.)

While fifty years ago the history of mathematics was focused, understandably, on elite

\footnotetext{
${ }^{6}$ Christopher Zeeman's analysis can be found at http://zakuski.math.utsa.edu/ gokhman/ecz/l_p.html. A robust response is given by Eleanor Robson, "Neither Sherlock Holmes nor Babylon: A Reassessment of Plimpton 322," Historia Mathematica, 2001, 28:167-206.
} 
mathematics and on mathematicians who were seen as the most important practitioners, there is now a much broader range of interests. Pioneering works included George Gheverghese Joseph's seminal The Crest of the Peacock, a polemical examination of mathematics in many cultures that challenges the Eurocentric tradition, and Petr Beckmann's remarkable A History of $P i$, which combines mathematical history with anti-Soviet polemic. ${ }^{7}$ The history of mathematics has been examined in relation to music (by Penelope Gouk, Benjamin Wardhaugh, and others) and the history of art (J. V. Field). ${ }^{8}$ The focus has moved from "great mathematicians" and the development of advanced mathematics to topics such as mathematics in popular culture (Wardhaugh's studies on humorous mathematical writers), the institutions that support mathematics (Adrian Rice and Robin Wilson on the London Mathematical Society, Marit Hartveit on the Edinburgh Mathematical Society, Alex D. D. Craik on mathematicians in Scotland), and mathematics in the context of twentieth-century modernism (Jeremy Gray). Where individual figures have been treated, the work is often interdisciplinary: examples include the work of Stephen Clucas and many others on John Dee; Daniel Mintz's recent thesis using present-day mathematical techniques to illuminate how Ptolemy gathered his geographical data; and the Thomas Harriot Seminars, which bring together scholars of this fascinating early modern figure, including Muriel Seltman, Jacqueline Stedall, and Matthias Schemmel, whose interest is primary mathematical, alongside many other students of Harriot's other contexts. ${ }^{9}$

Not only is research concerned with context and culture, but (in the United Kingdom and elsewhere) the diversity of writing for a broader readership is extremely encouraging and certainly demonstrates that, even in this branch of the discipline, context and culture are seen as central to our interest in the subject. The subtitle of Eleanor Robson's Mathematics in Ancient Iraq: A Social History makes clear the author's intent to move away from the more traditional concerns of the history of mathematics. Loren Graham and Jean-Michel Kantor's recent popular book argues that the unorthodox religious beliefs of Russian mathematicians helped them develop important ideas in set theory and investigates the social, sexual, and political relationships behind the success of the Moscow mathematical school; and Reinhard Siegmund-Schultze has explored the consequences of the migration of mathematicians fleeing Nazi Germany. ${ }^{10}$

With such a small community, the work of historians of mathematics will be read by mathematicians as well as by fellow historians. I have been particularly interested in the

\footnotetext{
${ }^{7}$ George Gheverghese Joseph, The Crest of the Peacock: Non-European Roots of Mathematics (London/New York: Tauris, 1991) (there have been several subsequent editions); and Petr Beckmann, A History of Pi (Boulder, Colo.: Golem, 1970).

${ }^{8}$ On the history of mathematics in relation to music see, e.g., Penelope Gouk, Music, Science, and Natural Magic in Seventeenth-Century England (New Haven, Conn.: Yale Univ. Press, 1999); Benjamin Wardhaugh, Music, Experiment, and Mathematics in England, 1653-1705 (Farnham, Surrey: Ashgate, 2008); and Fauvel et al., eds., Music and Mathematics (cit. n. 2). On its relation to the history of art see J. V. Field, The Invention of Infinity: Mathematics and Art in the Renaissance (Oxford: Oxford Univ. Press, 1997).

9 Jeremy Gray, Plato's Ghost: The Modernist Transformation of Mathematics (Princeton, N.J.: Princeton Univ. Press, 2008); Stephen Clucas, ed., John Dee: Interdisciplinary Studies in English Renaissance Thought (Dordrecht: Springer, 2006); Daniel V. Mintz, "Mathematics for History's Sake: A New Approach to Ptolemy's Geography" (Ph.D. diss., St. Andrews Univ., 2011); and Robert Fox, ed., Thomas Harriot: An Elizabethan Man of Science (Aldershot: Ashgate, 2000).

${ }^{10}$ Eleanor Robson, Mathematics in Ancient Iraq: A Social History (Princeton, N.J.: Princeton Univ. Press, 2008); Loren Graham and Jean-Michel Kantor, Naming Infinity: A True Story of Religious Mysticism and Mathematical Creativity (Cambridge, Mass.: Belknap, 2009); and Reinhard Siegmund-Schultze, Mathematicians Fleeing from Nazi Germany: Individual Fates and Global Impact (Princeton, N.J.: Princeton Univ. Press, 2009).
} 
reaction to two recent books that examine the reputation of mathematics and mathematicians. Patricia Fara's book on Newton's reputation met with a hostile reception in some mathematical quarters. Fara analyzes the growth of Newton's reputation and how the image of the great mathematician was adapted according to the needs and ideas of later generations: it seems that some readers felt that this investigation in some way questioned Newton's achievements. Similarly, Amir Alexander has explored the nineteenth-century construction of the mathematician as Romantic hero in Duel at Dawn: Heroes, Martyrs, and the Rise of Modern Mathematics. ${ }^{11}$ For me, this book threw light on the culture of mathematics that underlay my mathematical education and informed my career choices, but one mathematician's review did not share my enthusiasm. The sorts of strong feelings aroused among mathematicians by these books are inevitable when the traditions and practices of a discipline are investigated. Scientists are used to discussion and criticism of their methodologies by nonscientists - but perhaps the history of mathematics has been so dominated by those trained within the community that any questioning of mathematicians' values and motivations will be controversial.

This brings me to one last issue regarding history of mathematics. Whereas many of the ideas of science seem reasonably accessible to the layman (although so much nonsense has been written about quantum mechanics, in particular, that this must seem to practitioners to be a mixed blessing), a lot of modern pure mathematics is highly specialized. To understand much twentieth-century mathematics takes years of study. This growing specialization, which means that many mathematicians stick to their own narrow field, and the sheer difficulty of much modern mathematics create problems for the historian. If it takes several years of study to be in a position to read contemporary mathematical papers, can the history be written only by practitioners? How can an outsider be in a position to offer a detached view of, for example, the work in the second half of the twentieth century that led to the classification of the finite simple groups? This problem must also arise in the history of science, but it seems to me to be particularly acute in mathematics, and especially in recent pure mathematics.

So where does the history of mathematics stand in the United Kingdom today? As I have argued, the discipline has learned from the history of science that culture and context deserve attention and that a variety of sophisticated approaches are possible and desirable. Whereas the history of science has become established as an academic discipline with (albeit limited) career opportunities, university departments, and taught courses, the history of mathematics has a somewhat marginal existence, with its professional practitioners scattered, few opportunities for planned career development, and relatively few opportunities for doctoral training. Nevertheless, history of mathematics is healthy, moving in new directions and increasingly making valuable connections with other disciplines. History is being used to motivate the study of mathematics by schoolchildren and undergraduates, and those enthused by the subject are supporting a prolific range of popular publications. Above all, there is a diverse community of amateur historians and enthusiasts. Inevitably some of these, with their insular approach, follow a mode of history that now seems obsolete to historians. Nevertheless, much of the work in the history of mathematics over the last thirty years shows that the subject is developing and engaging with the ideas and practitioners of other disciplines.

Two major recent books exemplify my reasons for reasonable optimism about the

${ }^{11}$ Patricia Fara, Newton: The Making of Genius (London: Macmillan, 2002); and Amir Alexander, Duel at Dawn: Heroes, Martyrs, and the Rise of Modern Mathematics (Cambridge, Mass.: Harvard Univ. Press, 2010). 
future of the history of mathematics. The contributors to Robson and Stedall's Oxford Handbook of the History of Mathematics present a diverse panorama of sophisticated approaches to the history of mathematics: this exciting volume offers an inspirational range of new directions. Meanwhile, Timothy Gowers's recent Princeton Companion to Mathematics, of which the historian June Barrow-Green was an associate editor, includes a wealth of more traditional historical material, showing how the mathematical community values the history of its subject and its practitioners. ${ }^{12}$

While it remains to be seen how much of my optimism will survive the current shake-up of U.K. higher education-funding changes will affect the place of history in mathematics degree courses, and the discipline is not necessarily well placed to benefit from the focus on the "impact" of research that will influence the direction of research funding-the rapprochement with the ideas of the history of science community that I believe we are witnessing augurs well for the future.

\footnotetext{
${ }^{12}$ Eleanor Robson and Jacqueline Stedall, eds., The Oxford Handbook of the History of Mathematics (Oxford: Oxford Univ. Press, 2009); and Timothy Gowers, June Barrow-Green, and Imre Leader, eds., The Princeton Companion to Mathematics (Princeton, N.J.: Princeton Univ. Press, 2008).
} 